\title{
Sorption of volatile phenols by yeast cell walls
}

\author{
Nerea Jiménez-Moreno \\ Carmen Ancín-Azpilicueta
}

Department of Applied Chemistry, Universidad Pública de Navarra,

Pamplona, Spain
Correspondence: Carmen Ancín-Azpilicueta Department of Applied Chemistry, Universidad Pública de Navarra, Campus Arrosadía s/n, 31006 Pamplona, Spain $\mathrm{Tel}+34948168909$

Fax +34948I69606

Email ancin@unavarra.es
Abstract: Yeast walls can retain different wine compounds and so its use is interesting in order to eliminate harmful substances from the must which affect alcoholic fermentation (medium chain fatty acids) or which affect wine quality in a negative way (ethyl phenols, ochratoxin A). The aim of this study was to examine the capacity of commercial yeast cell walls in eliminating volatile phenols (4-ethylphenol and 4-ethylguaiacol) from a synthetic wine that contained $1 \mathrm{mg} / \mathrm{L}$ of each one of these compounds. The binding of these compounds to the wall was quite fast which would seem to indicate that the yeast wall-volatile compound union is produced in the outer surface layers of this enological additive. The cell walls used reduced the concentration of 4-ethylphenol and 4-ethylguaiacol, although it would seem that on modifying the matrix of the wine the number of free binding sites on the walls is also modified.

Keywords: volatile phenols, yeast cell walls, wine, sorption

\section{Introduction}

Volatile phenols are compounds that in high concentrations in wines, they can become spoilage compounds. 4-Ethylphenol and 4-ethylguaiacol are the identified volatile phenolic compounds associated with off-odor in wine (barnyard, horse sweat, band-aid, burnt plastic, wet animal). ${ }^{1}$ Among the yeasts that may be present in wine, Brettanomyces possesses the metabolic ability to enzymatically decarboxylate hydroxycinnamic acids to produce ethyl derivatives. ${ }^{2}$ Furthermore, it has been observed that in wine with "Brett" character, sensory profiles showed an increase in plastic odors and a decrease in fruit odors. ${ }^{1}$ Viable Brettanomyces were present on the walls and the soil of damp cellars. ${ }^{3}$ Likewise, Brettanomyces has been isolated in fermenting grape must from around the world (France, Germany, Italy, Spain, South Africa, Uzbekistan, New Zealand). ${ }^{1}$ However, the greatest problem of Brettanomyces contamination in a winery is found especially in old barrels. ${ }^{4,5}$

The cell wall protects yeast against lysis and determines its cellular form. Yeast cell wall accounts for $15 \%-25 \%$ of the dry weight although this quantity depends on the method of wall preparation. ${ }^{6,7}$ Its composition depends on various factors such as yeast species, nutrients from the culture medium, cellular size, mutations, sporulation. ${ }^{8}$ The cell wall of Saccharomyces cerevisiae is organized into two layers that are made up of only four classes of macromolecules, mannoproteins, $\beta 1$,6-glucan, $\beta 1$,3-glucan and chitin (Figure 1); these components are all interconnected by covalent bonds. ${ }^{9}$ The fraction of mannoproteins is the most external of the yeast wall and is tethered by a relatively short $\beta 1$,6-glucan chain of about 140 glucose residues to a $\beta 1,3$-glucan chain of approximately 1500 sugar residues. ${ }^{10,11}$ Chitin is linked to non-reducing branches of the $\beta 1,3$-glucan and the $\beta 1,6$-glucan. ${ }^{12,13}$ However, the cell wall is a dynamic structure and responds to changing external conditions and internal stimuli due to its composition and architecture. ${ }^{14}$ Yeast walls have the capacity to bind different wine compounds, so that its use is interesting for removing undesirable compounds present in must which affect alcoholic fermentation or which have a negative impact on the wine quality. Yeast walls bind toxic substances for fermentation such as the medium chain 
CELL WALL MANNOPROTEIN

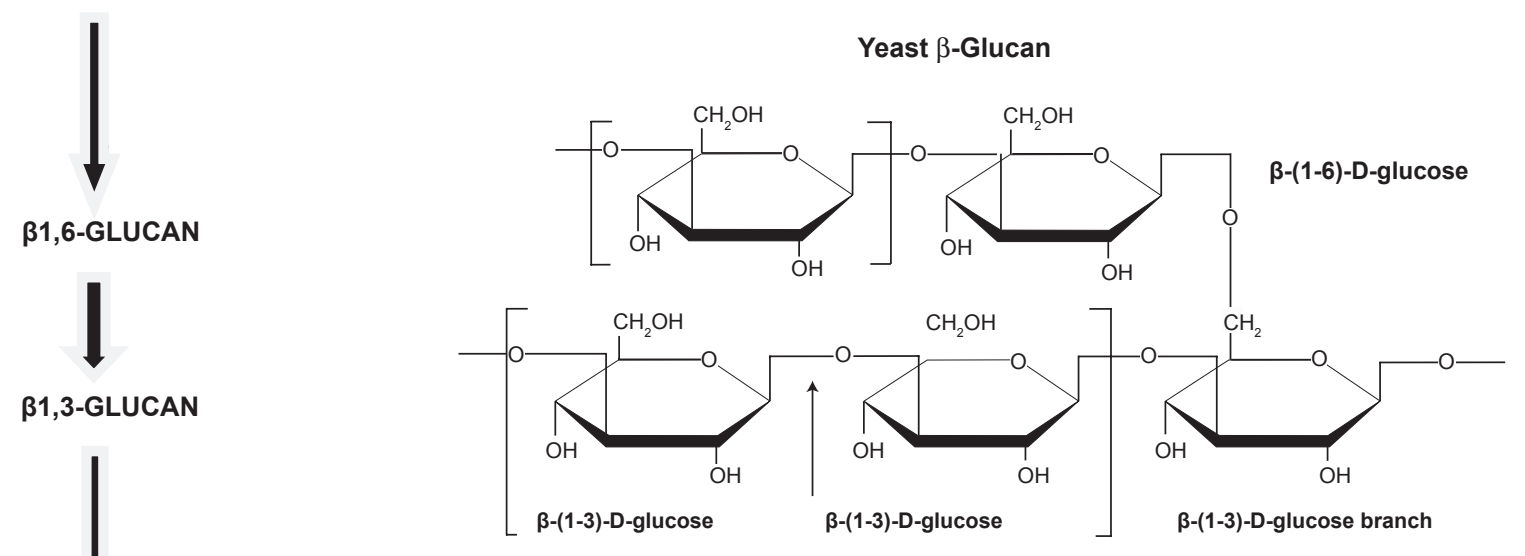

Polymer of $\beta-(1-3)$-glyco pyranosyl units with branching at $\beta-(1-6)-D-g y l c o p y r a n o s y l$

CHITIN

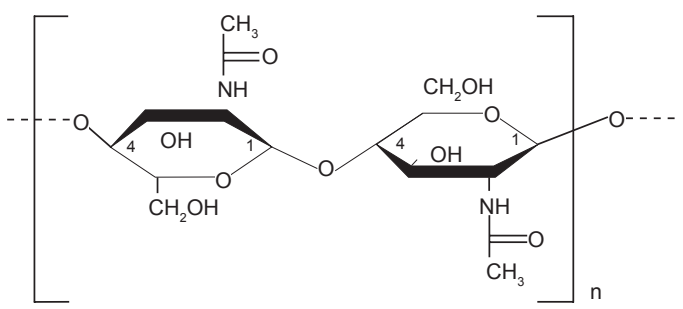

Figure I Structure of Saccharomyces cerevisiae cell wall.

saturated fatty acids, ${ }^{15}$ which are toxic for cells and cause a synergetic action with ethanol so that they could provoke a stuck fermentation. Cell wall mannoproteins could be implicated in the ochratoxin A adsorption from contaminated grape must. ${ }^{16,17}$ Likewise, Voilley and Lubbers ${ }^{18}$ found that there exist interactions between aroma compounds and other nonvolatile components that can be found in wine such as yeast walls, mannoproteins, bentonite or smaller molecules such as ethanol.

The aim of this work was to examine the volatile phenols (4-ethylphenol and 4-ethylguaiacol) removal ability of commercial yeast cell walls from a synthetic wine containing these compounds at a concentration of $1 \mathrm{mg} / \mathrm{L}$. To do so, an incubation of these compounds with yeast walls was made at controlled temperature both in combined form and in separate form, and the concentrations of these compounds after incubation were quantified. The experiment was carried out with and without stirring of the medium.

\section{Material and methods}

\section{Samples and experimental design}

The commercial cell walls used in this study come from S. cerevisiae. The chemical composition of these yeast walls is shown in Table 1. In this study different experiments were carried out in order to determine the binding of 4-ethylphenol and 4-ethylguaiacol to the commercial yeast walls added to a synthetic wine. The synthetic wine (alcohol 13\%, v/v) was prepared by diluting $6 \mathrm{~g}$ of tartaric acid (Sigma-Aldrich Inc., St Louis, MO, USA) and $130 \mathrm{~mL}$ of ethanol (Merck, Darmstadt, Germany) in de-ionized water up to $1 \mathrm{~L}$; the $\mathrm{pH}$ of this wine was adjusted to 3.2 with $\mathrm{NaOH} 3 \mathrm{M}$. All the experiments were carried out in $100 \mathrm{~mL}$ Erlenmeyer flasks, in which $100 \mathrm{~mL}$ of synthetic wine was introduced along with $5 \mathrm{~g} / \mathrm{L}$ of yeast walls. These flasks remained in a heater Selecta Medilow-S (Barcelona, Spain) at a controlled temperature of $20 \pm 1{ }^{\circ} \mathrm{C}$. The same wine was kept at the same temperature but without yeast walls to be used as a control sample. Firstly, sorption kinetics for both volatile

Table I Chemical composition of the cell walls used

\begin{tabular}{ll}
\hline Compounds & $\%$ \\
\hline Dry extract & $96 \pm 2$ \\
Glucans & $55 \pm 5$ \\
Mannans & $15 \pm 5$ \\
Lipids & $18-22$ \\
Proteins & $12-18$ \\
Chitin & $1-2$ \\
\hline
\end{tabular}


phenols were studied in order to determine the time where the equilibrium was reached between the retained volatile phenol by the yeast walls and the same compound dissolved in synthetic wine. To do so, 11 Erlenmeyer flasks were introduced in the heater with $1 \mathrm{mg} / \mathrm{L}$ of volatile phenols (4-ethylphenol, 4-ethylguaiacol) and $5 \mathrm{~g} / \mathrm{L}$ of yeast walls at $20 \pm 1{ }^{\circ} \mathrm{C}$ without magnetic stirring. Afterwards, the different flasks were taken out at different contact times between yeast walls and volatile compounds. Once the equilibrium time for 4-ethylphenol and 4-ethylguaiacol was determined, the sorption experiments of these compounds were carried out both with and without stirring of the samples. The experiment was made in Erlenmeyer flasks adding separately $1 \mathrm{mg} / \mathrm{L}$ of 4-ethylphenol or $1 \mathrm{mg} / \mathrm{L}$ of 4-ethylguaiacol to the synthetic wine. The experiment was also made adding the two compounds $(1 \mathrm{mg} / \mathrm{L}$ of 4 -ethylphenol and $1 \mathrm{mg} / \mathrm{L}$ of 4-ethylguaiacol) at the same time to the synthetic wine. The Erlenmeyer flasks were kept in the heater $\left(20 \pm 1{ }^{\circ} \mathrm{C}\right)$ for the time determined in the sorption kinetics experiment. Half of the flasks were kept with magnetic stirring and the rest without stirring. The experiments were carried out in duplicate. The percentage of sorption found in this study represent the difference between the concentration of volatile compound in the control sample and the concentration of this compound in the sample with yeast walls.

\section{Analysis of 4-ethylphenol and 4-ethylguaiacol}

The extraction of 4-ethylphenol and 4-ethylguaiacol was carried out following the method outlined by López and colleagues. ${ }^{19}$ For this extraction prepacked cartridges $(3 \mathrm{~mL}$ total volume) filled with $200 \mathrm{mg}$ LiChrolut EN resins (Merck) were placed in the extraction system (Vac Elut 20 station from Varian, Harbor City, CA, USA) and conditioned by rinsing with $4 \mathrm{~mL}$ of dichloromethane HPLC quality (Panreac, Barcelona, Spain), $4 \mathrm{~mL}$ of methanol HPLC quality (Scharlau, Barcelona, Spain) and finally, with $4 \mathrm{~mL}$ of water ethanol mixture $(12 \%, \mathrm{v} / \mathrm{v})$. An amount of $50 \mathrm{~mL}$ of synthetic wine were passed through the solid-phase extraction (SPE) cartridge at $2 \mathrm{~mL} / \mathrm{min}$. Afterwards, the sorbent was dried by letting air pass through it for $20 \mathrm{~min}$. Analytes were recovered by elution with $1.3 \mathrm{~mL}$ of dichloromethane of HPLC quality (Panreac).

The chromatographic analyses of 4-ethylphenol and 4-ethylguaiacol were carried out with a GC-MS Shimadzu (Kyoto, Japan), following the method outlined by Garde and colleagues. ${ }^{4}$ A DB-WAX capillary column (30 $\mathrm{m} \times 0.25 \mathrm{~mm}$ i.d. and $0.25 \mu \mathrm{m}$ film thickness) with stationary phase of polyethylene glycol bonded and cross-linked (Cromlab, Barcelona, Spain) was used. The volume of sample injected was $1 \mu \mathrm{L}$ in all cases. Ionization was produced by electronic impact at $70 \mathrm{eV}$. The internal standard used was 3,4-dimethylphenol (Merck). Standard solutions were prepared from Sigma-Aldrich reagents, dissolved in synthetic wine.

\section{Results and discussion Composition of cell walls used}

The cell walls of $S$. cerevisiae used in this work contained $55 \%$ approximately of glucans (Table 1). The reported glucan content of cell walls of $S$. cerevisiae ranges from 30 to $60 \%$ depending on the study. ${ }^{20,21}$ Fleet and Manners ${ }^{11}$ reported a value of $60 \%$ and suggested that lower values might be due to glucan degradation during wall preparation. Mannan represents between $25 \%$ and $50 \%$ of the wall of $S$. cerevisiae. ${ }^{20,21}$ In our case, the mannan content of the yeast walls used (Table 1) was somewhat lower than these values due to the fact that the accuracy and reliability of these content values depend on the purity of the wall preparation and their degree of contamination with cytoplasmic and plasma membrane material. ${ }^{8}$ The lipid content of the cell walls used in this study would have come from plasma membrane since the cell walls of $S$. cerevisiae do not contain these type of substances. The plasma membrane might not cleanly detach from the wall during cell disruption, so that lipid content of the purified wall may really reflect membrane contamination. ${ }^{8}$ Protein values for walls of $S$. cerevisiae were iniatially reported as around $13 \%{ }^{22}$ and supported by values near $15 \%$ reported in later studies. ${ }^{20,21}$ These values are consistent with those found in the yeast walls used in this study (Table 1). The chitin content found in the yeast walls used in this study $(1 \%-2 \%)$ are consistent with the values obtained by other authors..$^{23,24}$

\section{Sorption kinetics of 4-ethylphenol and 4-ethylguaiacol at yeast walls}

As can be seen in Figure 2, the binding of 4-ethylphenol and 4-ethylguaiacol to the yeast walls was very fast. For both volatile phenols the equilibrium time required was about three hours although after the first two hours important changes in the concentration of these two compounds were hardly observed. Judging from this rapid sorption, it is likely that these compounds bound to the most external surface of the yeast walls which is made up of mannoproteins, and these macromolecules would be the ones mainly responsible for the binding of 4-ethylphenol and 4-ethylguaiacol to the 


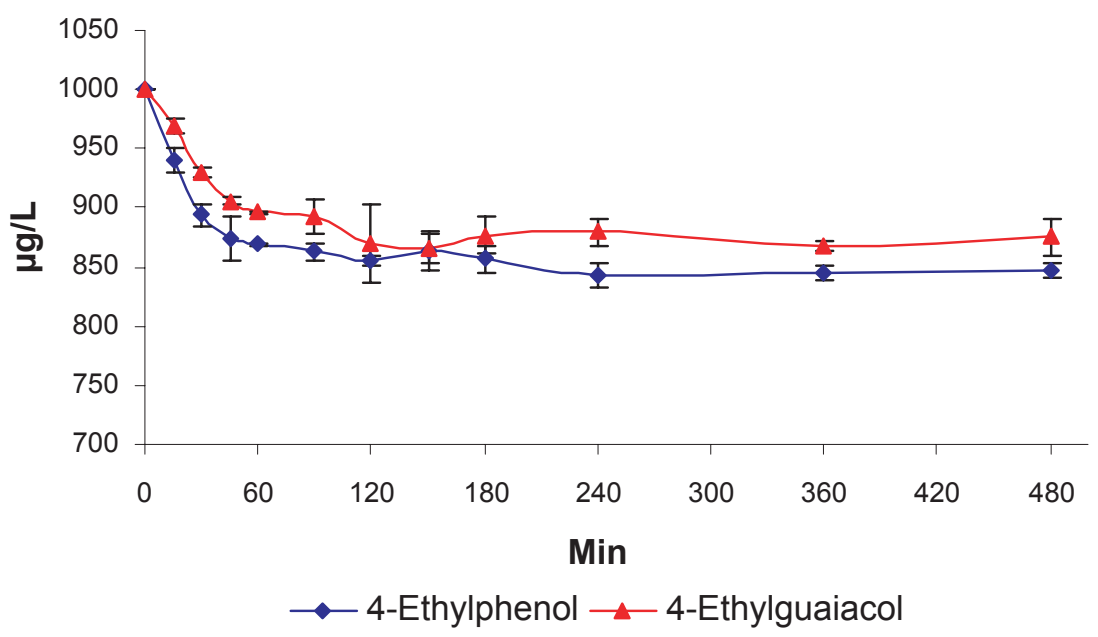

Figure 2 Kinetics of sorption of 4-ethylphenol and 4-ethylguaiacol by $5 \mathrm{~g} / \mathrm{L}$ of yeast walls at $20^{\circ} \mathrm{C}$.

cell walls. It is likely that the union between the volatile phenols studied and the yeast walls was produced through weak electrostatic interactions or through hydrogen bridges; in the synthetic medium used in this work no possibility exist of enzymatic or chemical reactions. This data coincides with the results of Chassagne and colleagues, ${ }^{25}$ who observed a rapid sorption of these compounds to yeast lees due to a rapid attachment of these molecules to the surface of the yeast. Likewise, Aksu and Dönmez ${ }^{26}$ obtained similar kinetics on studying the biosorption characteristics of some yeasts for Remazol Blue reactive dye and they concluded that the sorption occurs predominantly by surface binding and that available sites on the sorbent are the limiting factor for the sorption. Other authors have also observed that the saturation of the sorbent substrate (yeast walls, yeast lees) is the limiting factor in the sorption process of volatile compounds. ${ }^{27,28}$

\section{Sorption experiments}

When the experiment was carried out with the volatile phenols separately and without stirring, the concentration of 4-ethylphenol and 4-ethylguaiacol diminished in the experimental samples ( $12.1 \%$ and $10.1 \%$, respectively) in comparison with the control samples (Figures 3a, 3b). The sorption of 4-ethylphenol and 4-ethylguaiacol to the yeast walls could be due to their binding to the residual lipids as well as to the interaction of 4-ethylphenol and 4-ethylguaiacol, positively charged compounds, with the surface of the cell walls. In these volatile phenols, the proton of the hydroxyl group present in both molecules would be susceptible to forming hydrogen bridges as they would have a positive charge due to the acid medium. The chemical structure of these compounds is shown in Figure 4. In fact, the carbohydrate side chains of the cell surface mannoproteins contain multiple phosphodiester bridges, resulting in numerous negative charges at the cell surface. ${ }^{29}$ Some studies ${ }^{27,30}$ have related the hydrophobicity of the volatile compounds with their retention by different macromolecules or by yeast walls. The compounds under study in this work show a low polarity, where the hydrophobic constant of 4-ethylphenol $(\log \mathrm{P}=2.55)$ is somewhat greater than the 4-ethylguaiacol $(\log \mathrm{P}=2.38)$. These values of $\log \mathrm{P}$ are estimations obtained from Syracuse Research Corporation ${ }^{31}$ using an atom/fragment contribution method. This difference in hydrophobicity could explain the little differences observed between 4-ethylphenol and 4-ethylguaiacol in their binding to the yeast walls. The hydrophobicity of both molecules could be an obstacle to their binding to the yeast walls since wine is an aqueous medium and these substances would form agglomerations which would hinder their binding to the yeast walls. The surface properties of the yeast cell such as hydrophobicity, electrical charge, permeability, flocculence, sexual agglutinability and pathogenicity are determined by the external protein layer. ${ }^{14}$

Chassagne and colleagues ${ }^{25}$ added 4-ethylphenol and 4-ethylguaiacol along with $15 \mathrm{~g} / \mathrm{L}$ of fresh yeast lees to a model wine with a $\mathrm{pH}$ of 3.5 and an alcoholic level of $12 \%$ $(\mathrm{v} / \mathrm{v})$, the experiments were carried out at $15{ }^{\circ} \mathrm{C}$; they found that $33 \%$ of 4 -ethylphenol and $26 \%$ of 4 -ethylguaiacol were bound to the yeast lees. The greater binding of these compounds to the lees than to the yeast walls observed in our study, is probably due to the fact that yeast lees, as well as containing yeast walls, contain other macromolecules that can also bind compounds present in the medium. In this sense, various authors have found interactions between volatile 


\section{a)}

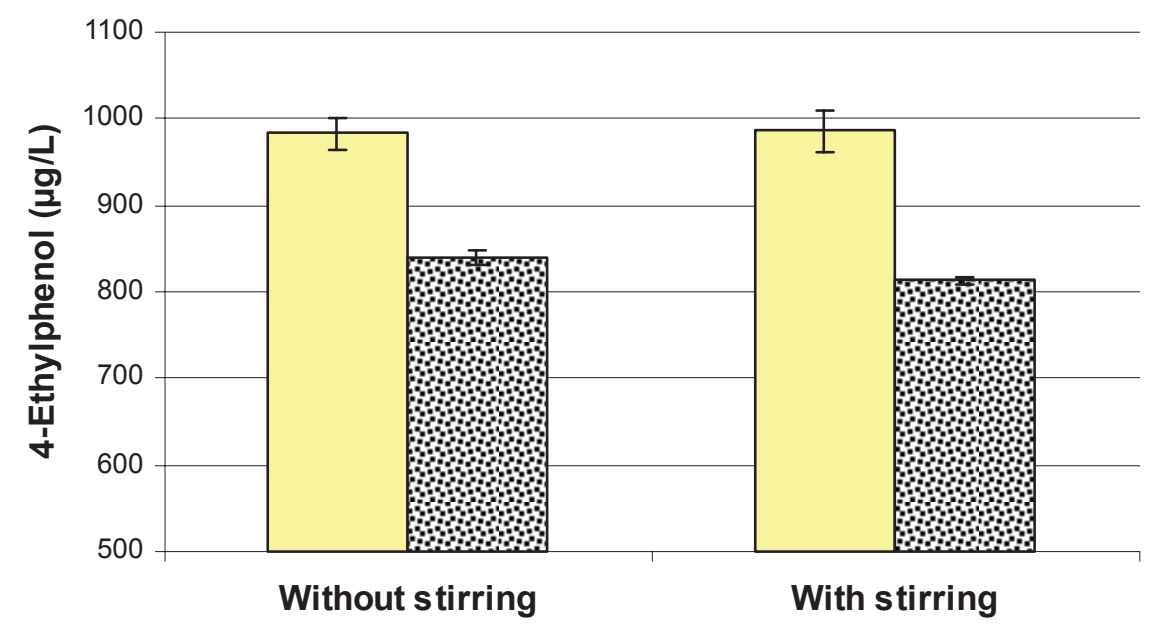

b)

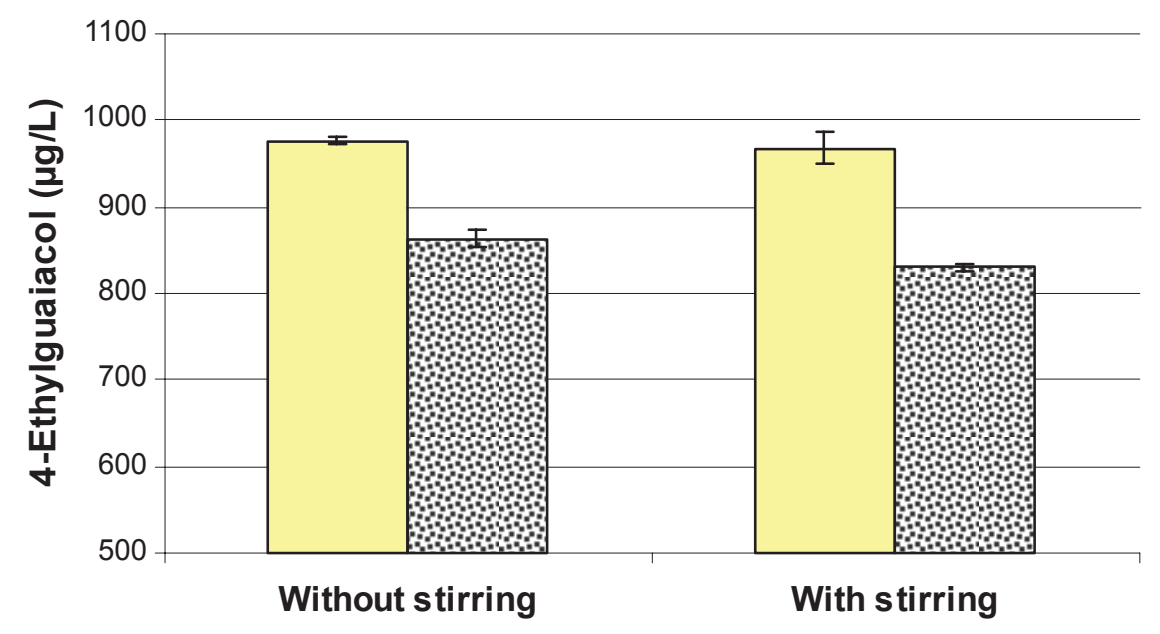

Control 圈 Yeast walls

Figure 3 Sorption experiments with 4-ethylphenol a) and 4-ethylguaiacol b) individually without stirring and with stirring.

compounds and different substances present in yeast lees such as polysaccharides, polyphenols, or $(+)$ catechin..$^{32-36}$ Razmkhab and colleagues ${ }^{37}$ found that yeast walls were the active support for the adsorption of browning compounds, but their efficiency was much lower than that of an equivalent amount of the yeast cells from which they were obtained. In addition, yeast walls from different yeast strains could show a different ability to bind volatile compounds as the composition of yeast cell walls would vary depending on the species and strain of the yeast. ${ }^{8}$ Consequently, given that the level of binding depends on the nature of the sorbent and of the volatile compound, ${ }^{18,36}$ the composition of the yeast walls will influence the level of sorption. Chalier and colleagues ${ }^{36}$ found different responses in studying the interactions between mannoproteins coming from different yeast strains and some volatile compounds. Various authors have identified the phosphorylated side chains of the yeast mannoproteins, responsible for the negative charges of yeast surface, and have reported slight differences between S. cerevisiae strains..$^{38-40}$

On carrying out the same experiment with magnetic stirring, an increase in the sorption of both compounds was observed in comparison with the unstirred samples; the sorption was more important in the case of 4-ethylphenol than in the case of 4-ethylguaiacol. The concentration of 4-ethylphenol, after reaching the equilibrium in the experiment with stirring diminished compared to the control sample $(15.1 \%)$, and in the case of 4-ethylguaiacol this reduction 


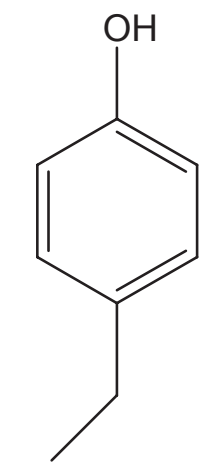

4-Ethylphenol

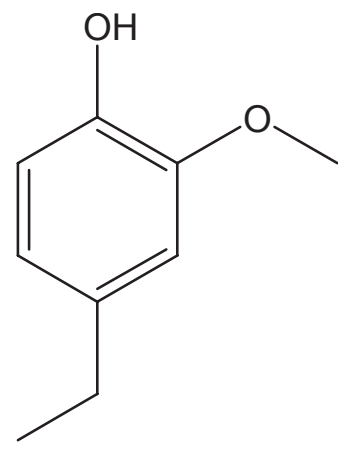

4-Ethylguaiacol
Figure 4 Chemical structures of 4-ethylphenol and 4-ethylguaiacol.

was somewhat lower (12.1\%) (Figures 3a, 3b). The higher binding of volatile phenols to the yeast walls would be due to the increase of the surface contact between the yeast walls and these compounds, which is produced by stirring. The stirring favors the binding of 4-ethylphenol and 4-ethylguaiacol to the yeast walls. Furthermore, the stirring would favor a better diffusion of these substances through the lattice that constitutes the cell wall so that the volatile phenols would gain access more easily to inner molecules within the yeast wall.

Finally, in this work the sorption of both 4-ethylphenol and 4-ethylguaiacol to the yeast walls was studied when they were both simultaneously present in the same sample, with and without stirring. Both volatile compounds bound to the yeast walls, although in both cases the sorption was lower than that observed in the experiments carried out with the compounds separately. In the experiment without stirring, the concentrations of 4-ethylphenol and 4-ethylguaiacol diminished $(6.3 \%$ and $1.6 \%$, respectively) in comparison with the control sample (Figure 5a). In the experiment with stirring both compounds bound to a more important extent to the yeast walls (4-ethylphenol, 8\% and 4-ethylguaiacol, 4.4\%) (Figure 5b). Both in the experiment without stirring and in the experiment with stirring, the diminution of the concentration

a) Without stirring

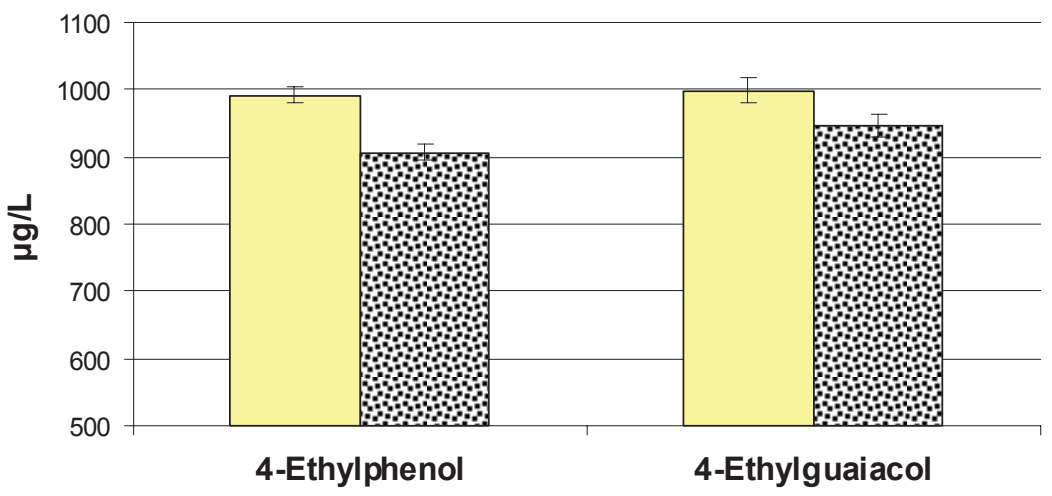

b) With stirring

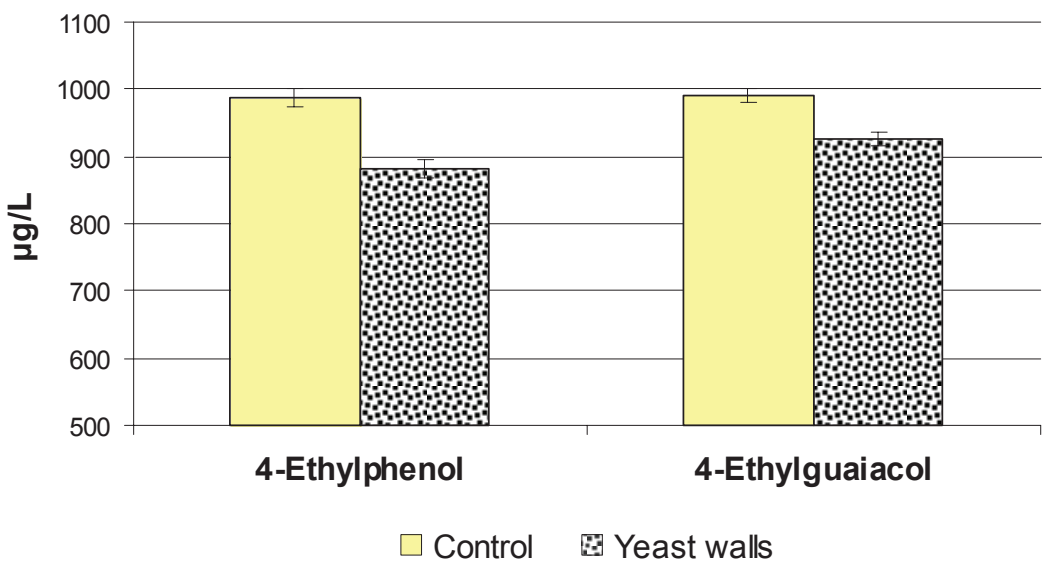

Figure 5 Sorption experiments with 4-ethylphenol and 4-ethylguaiacol jointly without stirring (a) and with stirring (b). 
of 4-ethylphenol in the presence of 4-ethylguaiacol was approximately half that of the reduction observed when 4-ethylguaiacol was not present in the sample. However, the reduction in the concentration of 4-ethylguaiacol observed when 4-ethylphenol was present in the sample is much less important than that observed in the individual experiments. This would seem to indicate, once again, a greater affinity for 4-ethylphenol by the yeast walls in comparison with 4-ethylguaiacol. In addition, the presence of 4-ethylphenol in the medium could make the sorption of 4-ethylguaiacol to the yeast walls more difficult. According to RamirezRamirez, and colleagues, ${ }^{41}$ wine constituents can affect to an important extent the partitioning of hydrophobic volatiles between liquid phase and sorbent. In this sense, the binding of 4-ethylphenol to the yeast walls could decrease the yeast sorption ability, preventing 4-ethylguaiacol from binding to an important extent to the walls. Seuvre and colleagues ${ }^{42}$ concluded that the interactions between macromolecules and aromatic compounds of a food, change the affinity of other volatile compounds for the matrix of the food by modifying the nature and the number of free binding sites. Ramirez-Ramirez and colleagues ${ }^{41}$ observed that the presence of ethyl esters increased the sorption of other aromatic compounds, such as benzaldehyde or 2-phenylethanol, by oak wood in a model system. In our case, the contrary would have been taking place, since it seems that the binding of 4-ethylphenol to the yeast walls could diminish the number of sorption sites or make them more inaccessible. Chalier and colleauges ${ }^{36}$ observed that the retention of volatile compounds by different mannoproteins depended on the accessibility of the binding site. Moreover, the importance of the geometry of the molecule has also been pointed out by Lübke and colleagues. ${ }^{43}$

\section{Conclusions}

The cell walls used in this study reduced the concentration of both 4-ethylphenol and 4-ethylguaiacol present in synthetic wine. Stirring favored the retention of these compounds to the yeast walls. The binding of these volatile phenols to the walls was very fast. This would seem to indicate that yeast wall-volatile compound sorption is produced in the outer layers of these enological additives. Furthermore, this sorption depends on the sites available on the sorbent, given that it would seem that the sorbent substrate was saturated on adding both compounds to the same synthetic wine. It would be interesting to consider further studies on the use of yeast walls in the removal of harmful components for the wine quality. Although lees and other more aggressive treatments could eliminate a greater amount of these substances, yeast walls present a lesser risk to wine quality.

\section{Disclosure}

The authors report no conflicts of interest in this work.

\section{References}

1. Licker JL, Acree TE, Henick-Kling T. What is Brett (Brettanomyces) flavour? A preliminary investigation. In: Waterhouse AL, Ebeler SE, editors. Chemistry of wine flavour. Washington: American Chemical Society; 1998. p. 96-115.

2. Edlin DAN, Narbad A, Dickinson JR, Lloyd D. The biotransformation of simple phenolic compounds by Brettanomyces anomalus. FEMS Microbiol Lett. 1995;125:311-316.

3. Peynaud E, Domercq S. Sur les Brettanomyces isolés de raisins et de vins. Arch Mikrobiol. 1956;24:266-280.

4. Garde T, Rodríguez S, Ancín C. Volatile composition of aged wine in used barrels of French oak and American oak. Food Res Int 2002;35:603-610.

5. Garde T, Torrea D, Ancín C. Changes in the concentration of volatile oak compounds and esters in red wine stored for 18 months in re-used French oak barrels. Australian J Grape Wine Res. 2002;8:140-145.

6. Fleet GH, Phaff HJ. Effect of glucanases of yeast and bacterial origin on cell walls of Schizosaccharomyces species. Proc. 3rd Internat. Symp. Yeast Protoplasts; Salamanca, Spain: Academic Press, London; 1973.

7. Fleet GH, Phaff HJ. Glucanases in Schizosaccharomyces. Isolation and properties of the cell wall associated $\beta$ - $(1 \rightarrow 3)$-glucanases. J Biol Chem. 1974;249:1717-1728.

8. Fleet GH. Cell walls. In: Rose AH, Harrison JS, editors. The Yeasts. Yeast organelles (Volume 4). San Diego: Academic Press Inc; 1991. p. $199-277$.

9. Klis FM, Mol P, Hellingwerf K, Brul S. Dynamics of cell wall structure in Saccharomyces cerevisiae. FEMS Microbiol Rev. 2002;26:239-256.

10. Manners DJ, Masson AJ, Patterson JC, Bjorndal H, Lindberg B. The structure of a $\beta-(1-6)$-D-glucan from yeast cell walls. Biochem $J$. 1973;135:31-36.

11. Fleet GH, Manners DJ. Isolation and composition of an alkali-soluble glucan from the cell walls of Saccharomyces cerevisiae. J Gen Microbiol. 1976;94:180-192.

12. Kollar R, Petrakova E, Ashwell G, Robbins PW, Cabib E. Architecture of the yeast cell wall. The linkage between chitin and $\beta(1 \rightarrow 3)$-glucan. J Biol Chem. 1995;270:1170-1178.

13. Kollar R, Reinhold BB, Petrakova E, et al. Architecture of the yeast cell wall. $\beta(1 \rightarrow 6)$-glucan interconnects mannoprotein, $\beta(1 \rightarrow 3)$-glucan, and chitin. J Biol Chem. 1997;272:17762-17775.

14. Klis FM. Review: Cell wall assembly in yeast. Yeast. 1994;10:854-869.

15. Lafon-Lafourcade S, Geneix C, Ribéreau-Gayon P. Inhibition of alcoholic fermentation of grape must by fatty acids produced by yeast and their elimination by yeast ghosts. Appl Environ Microbiol. 1984;47:1246-1249.

16. Bejaoui H, Mathieu F, Taillandier P, Lebrihi A. Ochratoxin A removal in synthetic and natural grape juices by selected oenological Saccharomyces strains. J Appl Microbiol. 2004;97:1038-1044.

17. Caridi A, Galvano F, Tafuri A, Ritieni A. Ochratoxin A removal during winemaking. Enzyme Microb Technol. 2006;40:122-126.

18. Voilley A, Lubbers S. Flavor-matrix interactions in wine. In: Waterhouse AL, Ebeler SE, editors. Chemistry of wine flavour. Washington: ACS Symposium Series, American Chemical Society; 1998. p. 217-229.

19. López R, Aznar M, Cacho J, Ferreira V. Determination of minor and trace volatile compounds in wine by solid-phase extraction and gas chromatography with mass spectrometric detection. $J$ Chromatogr A. 2002;966:167-177.

20. McMurrough I, Rose AH. Effect of growth rate and substrate limitation on the composition and structure of the cell wall of Saccharomyces cerevisiae. Biochem J. 1967;105:189-203. 
21. Ramsay AM, Douglas LJ. Effect of phosphate limitation of growth on the cell wall and lipid composition of Saccharomyces cerevisiae. J Gen Microbiol. 1979;110:185-191.

22. Northcote DH, Horne RW. The chemical composition and structure of the yeast cell wall. Biochem J. 1952;51:232-236.

23. Cabib E, Bowers B. Chitin and yeast budding. Localization of chitin in yeast bud scars. J Biol Chem. 1971;246:152-159.

24. Beran K, Holan Z, Baldrian J. The chitin-glucan complex in Saccharomyces cerevisiae. I. IR and X-ray observations. Folia Microbiol (Praha). 1972;17:322-330.

25. Chassagne D, Guilloux-Benatier M, Alexandre H. Sorption of volatile phenols by yeast lees. Food Chem. 2005;91:39-44.

26. Aksu Z, Dönmez G. A comparative study on the biosorption characteristics of some yeasts for Remazol Blue reactive dye. Chemosphere. 2003;50:1075-1083.

27. Lubbers S, Charpentier C, Feuillat M, Voilley A. Influence of yeast walls on the behavior of aroma compounds in a model wine. Am JEnol Vitic. 1994;45:29-33.

28. Jiménez-Moreno N, Ancín-Azpilicueta C. Binding of oak volatile compounds by wine lees during simulation of wine ageing. LWT-Food Sci Technol. 2007;40:619-624.

29. Jigami Y, Odani T. Mannosylphosphate transfer to yeast mannan. Biochim Biophys Acta. 1999;1426:335-345.

30. Voilley A, Beghin C, Charpentier C, Peyron D. Interactions between aroma substances and macromolecules in a model wine. Lebensm-Wiss u-Technol. 1991;24:469-472.

31. Syracuse Research Corporation. 2007. Cited on Nov 16, 2008. Available from: http://www.syrres.com/esc/physdemo.htm.

32. Dufour $\mathrm{C}$, Bayonove CL. Influence of wine structurally different polysaccharides on the volatility of aroma substances in a model system. J Agric Food Chem. 1999;47:671-677.

33. Dufour C, Bayonove CL. Interactions between wine polyphenols and aroma substances. An insight at the molecular level. J Agric Food Chem. 1999;47:678-684.
34. Escalona H, Homman-Ludiye M, Piggott JR, Paterson A. Effect of potassium bitartrate, $(+)$-catechin and wood extracts on the volatility of ethyl hexanoate and octanal in ethanol/water solutions. Lebensm-Wiss u-Technol. 2001;34:76-80.

35. Mazauric JP, Salmon JM. Interactions between yeast lees and wine polyphenols during simulation of wine aging: I. Analysis of remnant polyphenolic compounds in the resulting wines. J Agric Food Chem. 2005;53:5647-5653.

36. Chalier P, Angot B, Delteil D, Doco T, Gunata Z. Interactions between aroma compounds and whole mannoprotein isolated from Saccharomyces cerevisiae strains. Food Chem. 2007;100:22-30.

37. Razmkhab S, López-Toledano A, Ortega JM, Mayen M, Merida J, Medina M. Adsorption of phenolic compounds and browning products in white wines by yeasts and their cell walls. J Agric Food Chem. 2002;50:7432-7437.

38. Cawley TN, Ballou CE. Identification of two Saccharomyces cerevisiae cell wall mannan chemotypes. J Bacteriol. 1972;111:690-695.

39. Antalis C, Fogel S, Ballou CE. Genetic control of yeast mannan structure. Mapping the first gene concerned with mannan biosynthesis. J Biol Chem. 1973;248:4655-4659.

40. Rosenfield L, Ballou CE. Genetic control of yeast mannan structure. Biochemical basis for the transformation of Saccharomyces cerevisiae somatic antigen. J Biol Chem. 1974;249:2319-2321.

41. Ramirez-Ramirez G, Chassagne D, Feuillat M, Voilley A, Charpentier C. Effect of wine constituents on aroma compound sorption by oak wood in model system. Am J Enol Vitic. 2004;55:22-26.

42. Seuvre AM, Espinosa-Díaz MA, Voilley A. Influence of the food matrix structure on the retention of aroma compunds. J Agric Food Chem. 2000;48:4296-4300.

43. Lübke M, Guichard E, Le Quéré JL. Infrared spectroscopic study of $\beta$-lactoglobulin interactions with flavour compounds. In: Roberts D, Taylor A, editors. Flavour Release. Washington: ACS Symposium Series, American Chemical Society; 2000. 